\title{
Land snails of Leptopoma Pfeiffer, 1847 in Sabah, Northern Borneo (Caenogastropoda: Cyclophoridae): an analysis of molecular phylogeny and geographical variations in shell form
}

\author{
Chee-Chean Phung ${ }^{1}$, Pooi-San Heng ${ }^{1}$, Thor-Seng Liew ${ }^{\text {Corresp. }}{ }^{1}$ \\ ${ }^{1}$ Institute for Tropical Biology and Conservation, Universiti Malaysia Sabah, Kota Kinabalu, Sabah, Malaysia \\ Corresponding Author: Thor-Seng Liew \\ Email address: thorsengliew@gmail.com
}

Leptopoma is a species rich genus with approximately 100 species documented. Specieslevel identification in this group has been based on shell morphology and colouration, as well as some anatomical features based on small sample sizes. However, the implications of the inter- and intra-species variations in shell form to the taxonomy of Leptopoma species and the congruency of its current shell based taxonomy with its molecular phylogeny are still unclear. There are four Leptopoma species found in Sabah, Borneo, and their taxonomy status remains uncertain due to substantial variation in shell forms. This study focuses on the phylogenetic relationships and geographical variation in shell form of three Leptopoma species from Sabah.The phylogenetic relationship of these species was first estimated by performing Maximum Likelihood and Bayesian analysis based on mitochondrial genes (16S and COI) and nuclear gene (ITS-1). Then, a total of six quantitative shell characters (i.e. shell height, shell width, aperture height, aperture width, shell spire height, and ratio of shell height to width) and three qualitative shell characters (i.e. shell colour patterns, spiral ridges, and dark apertural band) of the specimens were mapped across the phylogenetic tree and tested for phylogenetic signals. Data on shell characters of Leptopoma sericatum and Leptopoma pellucidum from two different locations (i.e. Balambangan Island and Kinabatangan) where both species occurred sympatrically were then obtained to examine the geographical variations in shell form. The molecular phylogenetic analyses suggested that each of the three Leptopoma species was monophyletic and indicated congruence with only one of the shell characters (i.e. shell spiral ridges) in the current morphological-based classification. Although the geographical variation analyses suggested some of the shell characters indicating inter-species differences between the two Leptopoma species, these also pointed to intra-species differences between populations from different locations. This study on Leptopoma species is based on small sample size and the findings appear only applicable to Leptopoma species in Sabah. Nevertheless, we anticipate this study to be a starting point for more 
detailed investigations to include the other still little-known (ca. 100) Leptopoma species and highlights a need to assess variations in shell characters before they could be used in species classification. we anticipate this study to be a starting point for more detailed investigations to include the other still little-known (ca. 100) Leptopoma species and highlights a need to assess variations in shell characters before they could be used in species classification. 
1 LAND SNAILS OF LEPTOPOMA PFEIFFER, 1847 IN SABAH, NORTHERN BORNEO 2 (CAENOGASTROPODA: CYCLOPHORIDAE): AN ANALYSIS OF MOLECULAR 3 PHYLOGENY AND GEOGRAPHICAL VARIATIONS IN SHELL FORM

4 Chee-Chean Phung, Pooi-San Heng, Thor-Seng Liew Institute for Tropical Biology and Conservation, Universiti Malaysia Sabah, Jalan UMS, 88400

6 Kota Kinabalu, Malaysia.

7 Corresponding author: Thor-Seng Liew (thorsengliew@gmail.com)

Abstract. Leptopoma is a species rich genus with approximately 100 species documented. Species-level identification in this group has been based on shell morphology and colouration, as well as some anatomical features based on small sample sizes. However, the implications of the inter- and intra-species variations in shell form to the taxonomy of Leptopoma species and the congruency of its current shell based taxonomy with its molecular phylogeny are still unclear. There are four Leptopoma species found in Sabah, Borneo, and their taxonomy status remains uncertain due to substantial variation in shell forms. This study focuses on the phylogenetic relationships and geographical variation in shell form of three Leptopoma species from Sabah.The phylogenetic relationship of these species was first estimated by performing Maximum Likelihood and Bayesian analysis based on mitochondrial genes (16S and COI) and nuclear gene (ITS-1). Then, a total of six quantitative shell characters (i.e. shell height, shell width, aperture height, aperture width, shell spire height, and ratio of shell height to width) and three qualitative shell characters (i.e. shell colour patterns, spiral ridges, and dark apertural band) of the specimens were mapped across the phylogenetic tree and tested for phylogenetic signals. Data on shell characters of Leptopoma sericatum and Leptopoma pellucidum from two different locations (i.e. Balambangan Island and Kinabatangan) where both species occurred sympatrically were then obtained to examine the geographical variations in shell form. The molecular phylogenetic analyses suggested that each of the three Leptopoma species was monophyletic and indicated congruence with only one of the shell characters (i.e. shell spiral ridges) in the current morphological-based classification. Although the geographical variation analyses suggested some of the shell characters indicating inter-species differences between the two Leptopoma species, these also pointed to intra-species differences between populations from different locations. This study on Leptopoma species is based on small sample size and the findings appear only applicable to Leptopoma species in Sabah. Nevertheless, we anticipate this study to be a starting point for more detailed investigations to include the other still little-known ( $\mathrm{ca}$. 100) Leptopoma species and highlights a need to assess variations in shell characters before they could be used in species classification.

\section{INTRODUCTION}

The terrestrial snail genus Leptopoma is one of 35 genera in the family Cyclophoridae (Kobelt, 1902), which has a wide global distribution range extending across much of the Oriental and 
Australasia zoogeographical regions. An early global overview of species-level diversity in Leptopoma species classified the genus into four subgenera with a total of 105 species (Kobelt, 1902). Several subsequent regional taxonomic reviews of Leptopoma were conducted for the Philippines (Zilch, 1956), South Asia (Gude, 1921), and most recently for Borneo (Vermeulen, 1999). To date, taxonomic works on Leptopoma (Kobelt, 1902; Gude, 1921; Zilch, 1954; Vermeulen, 1999) have been based mainly on shell morphology (i.e shell size, shape, colour pattern and sculpture). Besides shell morphology, other characters of the soft body such as radula, operculum, and genital duct have been used from time to time in the species delimitation (Sarasin \& Sarasin, 1899; Jonges, 1980). Although several species have been included in phylogenetic studies focussing on other taxa (Colgan et al., 2000, 2003, 2007; Lee et al. 2008a, 2008b; Nantarat et al., 2014a), little is known about the relationship within the genus Leptopoma itself.

The genus Leptopoma is widespread in the Philippines and the adjacent Malaysian state of Sabah, which is located in the northern part of Borneo (Godwin-Austen, 1891; Laidlaw, 1937; Vermeulen, 1999; Schilthuizen \& Rutjes, 2001; Uchidal et al., 2013). Currently, four Leptopoma species could be identified from the specimens collected in Sabah. Of these, Leptopoma undatum (Metcalfe, 1851) and Leptopoma atricapillum (Sowerby, 1843) can be found in Borneo and the Philippines (Vermeulen, 1999). Leptopoma sericatum (Pfeiffer, 1851) is distributed in Borneo (Vermeulen, 1999). Leptopoma pellucidum (Grateloup, 1840) is widely spread in Sabah but the actual global range is unknown due to taxonomy uncertainty (Vermeulen, 1999). Its putative synonym, L. vitreum (Lesson, 1830), has a wide range encompassing Taiwan, South Asia, and Papua New Guinea (Vermeulen, 1999).

Leptopoma undatum is readily distinguished from the others by its uniform white shell (translucent when young and opaque when old) and distinctive shell shape (i.e. relatively less convex whorls and sharply keeled at the last whorl). The other three species, Leptopoma atricapillum, L. sericatum and L. pellucidum, are very similar in terms of shell shape with all showing and sharing colour pattern polymorphism. L. atricapillum and L. sericatum, however have strongly-defined spiral ridges on the shell surface, with more pronounced spiral ridges in the former, whereas the spiral ridges of L. pellucidum are only weakly defined.

The Cyclophoridae represents the most diverse Caenogastropoda family, but is remains poorly resolved taxonomically. Delimitation among subgenera and species in Cyclophoridae has long been a conundrum for taxonomists due to exceptionally diverse variation in morphology (e.g. subgenera in genus Cyclophorus and Alycaeus (Kobelt, 1902; Gude, 1921)). Vermeulen (1999) identified two major challenges with using shell characters to discriminate between six species of Bornean Leptopoma. First, the majority of species are similar in shell morphology and this limits the number of shell characters that can be used as diagnostic characters at species level. Second, there appears to be a continuum of variation in some characters (i.e. size, shape, colour 
patterns), particularly between L. pellucidum and L. sericatum and this contributes to uncertainty when delimiting species. Thus it is clear that to date, the implications of the intra- and interspecific variation in shell morphology have not been studied systematically and comprehensively in the context of the taxonomy of this genus.

This study had three aims. (1) To estimate the molecular phylogenetic relationship of three similar yet polymorphic Leptopoma species in Sabah to investigate the monophyly of $L$. sericatum, L. pellucidum and L. atricapillum based on two mitochondrial genes (16S RNA and COI) and nuclear gene (ITS-1). (2) To test the phylogenetic signal of three qualitative and six quantitative shell characters to evaluate their reliability as diagnostic characters. (3) To compare the differences in shell characters of two Leptopoma species, L. sericatum and L. pellucidum, at two locations, where they co-occur and are abundant to understand the geographical variations in shell characters under consideration and further assess their reliability as diagnostic characters.

\section{MATERIALS AND METHODS}

All the Leptopoma specimens included in this study were obtained from the BORNEENSIS Mollusca collection at the Institute of Tropical Biology and Conservation in Universiti Malaysia Sabah. The collection houses more than 4000 specimens of Leptopoma spp. collected since 2000 from various locations in Sabah (Figure 1). From this comprehensive collection, 77 alcoholpreserved specimens of four species (L. sericatum, L. pellucidum, L. atricapillum, L. undatum) were selected for molecular analysis. 249 empty shells of adult snails of $L$. sericatum (114) and $L$. pellucidum (135) from Balambangan Island and the Kinabatangan region, where both species exist sympatrically were selected for morphological analysis (Supplementary File 1). These Leptopoma specimens were identified as either L. pellucidum or L. sericatum on the basis of the presence/absence of distinct spiral ridges on the shell (Vermeulen, 1999).

\section{Data Collection}

\section{Genetic Data}

Genomic DNA was extracted from a total of 77 individuals preserved in $70 \%$ ethanol, but sequence data for at least two genes could only generated for 17 of these (Table S1 in Supplementary File 2). DNA was extracted from foot tissue by using DNeasy extraction kit (Qiagen Inc., Hilden, Germany) according to manufacturer instructions. We used two mitochondrial genes, the protein coding COI (cytochrome oxidase 1) and the non-coding 16S rRNA, and one nuclear gene ITS-1 (internal transcribed spacer 1). Universal primers LCO1490 (5'-GGTCAACAAATCATAAAGATATTGG-3') and HCO2198 (5'TAAACTTCAGGGTGACCAAAAAATCA-3') were used to amplify and sequence COI (Folmer et al., 1994). The 16s rRNA region was amplified using primers 16Sar (5'CGCCTGTTTATCAAAAACAT-3') and 16Sbr (5'-CCGGTCTGAACTCAGATCACGT-3') (Kessing et al., 1989). ITS-1 region was PCR-amplified using the primers 5.8c (5'- 
120

121

122

123

124

125

126

127

128

129

130

131

132

133

134

135

136

137

138

139

140

141

142

143

144

145

146

147

148

149

150

151

152

153

154

155

156

157

158

GTGCGTTCGAAATGTCGATGTTCAA-3')

and

$18 d$

(5'CACACCGCCCGTCGCTACTACCGATTG-3') (Hillis \& Dixon, 1991). Thermal cycling was performed with pre-denaturation at $90^{\circ} \mathrm{C}$ for 2 minutes, denaturation at $94^{\circ} \mathrm{C}$ for 45 seconds, one minute of annealing at $55^{\circ} \mathrm{C}, 60^{\circ} \mathrm{C}$, and $54^{\circ} \mathrm{C}$ for COI, $16 \mathrm{~s}$, and ITS- 1 respectively, extension at $72^{\circ} \mathrm{C}$ for one minute followed by final extension at $72{ }^{\circ} \mathrm{C}$ for 5 minutes. The denaturation, annealing and extension steps were repeated for 35 cycles. The PCR products were sequenced at Macrogen, Inc. (Korea). All sequences were subsequently uploaded and stored in Barcoding of Life Database (BOLD, http://www.boldsystems.org, Ratnasingham \& Hebert, 2007), under the project title "Leptopoma in Sabah" (Code: LEPT).

\section{Shell Morphological Characters Data}

Shell form in this study included both quantitative (i.e size and shape) and qualitative (i.e colour patterns, spiral ridges and presence/absence dark apertural band) shell characters. These morphological characters were evaluated from the apertural view of the 264 shells examined in total (i.e. the 249 dry specimens and 14 adult specimens included in the phylogenetic analysis). First, high quality photographs were taken of the aperture of each shell with the aid of a Leica Stereo Microscope M205. Five quantitative linear measurements, namely shell height (SH), shell width $(\mathrm{SW})$, aperture height $(\mathrm{AH})$, aperture width $(\mathrm{AW})$, and shell spire height $(\mathrm{SpH})$ were then measured directly from the photographs using Leica Application Suite software (Fig. 2A). A sixth quantitative shell character - the ratio of shell height to width - was computed. Next, the states for two qualitative shell characters (i.e. eight distinct shell colour patterns and presence/absence of the dark apertural band) were recorded for each of the shells (Figs. 2C, 2D; see Table S2 in Supplementary File 2 for the descriptions of the eight shell colour patterns).

\section{Data Analysis}

\section{Molecular Phylogenetic Analysis}

In addition to the sequences collected from 17 specimens in this study, $16 \mathrm{~S}$ and COI sequences of L. tigris, L. vitreum and an outgroup species - Cyclophorus formosensis (Nevill, 1882) from Lee et al. (2008a) and Nantarat et al. (2014a) - were obtained from GenBank (Supplementary File S1, Page 1: Table S1 for informations of specimens). All the DNA sequences were aligned and checked manually using Bioedit v7.1.9 (Hall, 1999). In order to find the best-fit model of substitution, jModelTest2 (Darriba et al., 2012) as implemented in CIPRES portal (Miller et al., 2010) was performed based on corrected Akaike Information Criterion (AICc) for ITS-1 sequences, 16S sequences and each of the codon positions of COI sequences. Phylogenetic trees were estimated using Maximum likelihood (ML) and Bayesian Inference methods (BI) as implemented in CIPRES portal (Miller et al., 2010). ML analysis was conducted using RaxmlHPC2 (Stamatakis, 2014) with 1000 rapid bootstraps. BI analysis was performed using MrBayes v3.2.3 (Huelsen \& Ronquist, 2001). This consisted of running four simultaneous chains for 
159

160

161

162

163

164

165

166

167

168

169

170

171

172

173

174

175

176

177

178

179

180

181

182

183

184

185

186

187

188

189

190

191

192

193

194

195

196

197

198

100,000 generations and 10 sampling frequency. The first 250 trees were discarded as burn-in, while the rest were used to obtain the final consensus tree.

\section{Phylogenetic Signal Analysis}

Phylogenetic signal analysis was used to investigate the relationship between phylogeny and morphology, with all the analyses done in the $\mathrm{R}$ statistical environment, version 3.1.3 (R Core Team, 2015). The tips in the tree corresponding to juvenile specimens and outgroup taxa were excluded by using package 'ape' (Paradis et al., 2004). The final tree for phylogenetic signal analysis consisted of 14 adults of the three Leptopoma species, L. atricapillum, L. pellucidum, and L. sericatum. The six quantitative and three qualitative shell characters were mapped onto the tree by utilising package 'phytools'. Phylogenetic signals for each of these nine shell characters were examined using maximum likelihood $(\lambda)$ (Pagel, 1999) and K (Blomberg et al., 2003). The consensus tree was transformed into an ultrametric tree after which a lambda analysis was performed using the 'chronopl' function from the 'ape' package (Paradis et al., 2004). As a result, a chronogram was generated using penalised likelihood with an arbitrary lambda value of 0.1 , the alternative model. A null model, the Leptopoma phylogenetic tree with $\lambda=0$ (no phylogenetic signal), was generated using the 'rescale' function from the 'geiger' package (Harmon et al., 2008). The $\lambda$ value of each shell character was estimated for both models using the 'fitDiscrete' function for three qualitative shell characters and 'fitContinuous' function for six quantitative shell characters in the 'geiger' package (Harmon et al., 2008). Likelihood scores for the alternative and null models were compared by performing a likelihood ratio test in order to examine the phylogenetic signal in each shell character, wherein Blomberg's $\mathrm{K}$ was calculated using the 'physig' function from the 'phytool' package (Revell, 2012; R script in Supplementary File 3).

\section{Geographical Variation in Shell Morphology Analysis}

Two-way ANOVA tests were performed to determine if there were differences in the six quantitative shell characters between: (i) the two Leptopoma species (L. pellucidum and $L$. sericatum), and (ii) the two locations (Balambangan Island and Kinabatangan). In addition, the interaction effects of both factors (species and location) were tested. A Shapiro-Wilk test for normality (Shapiro \& Wilk, 1965), and a Levene's test (Brown \& Forsythe, 1974) for homogeneity of variance, revealed that some datasets were not normally distributed and showed non-homogeneity of variances (Table S3 \& S4 in Supplementary File 2). Nevertheless, two-way ANOVA tests were still conducted since the deviations of these datasets from the ANOVA assumption were considered not too serious, and the ANOVA was considered a robust test against the normality assumption (Zar, 1999).

Chi-square two-way contingency table tests were performed to determine whether the shell colour patterns and the presence/absence of a dark apertural band were associated with species identity and location respectively. Prior to the analyses, four two-way contingency tables 
199

200

201

202

203

204

205

206

207

208

209

210

211

212

213

214

215

216

217

218

219

220

221

222

223

224

225

226

227

228

229

230

231

232

233

234

235

236

237

238

were produced. These summarised frequencies as follows: (1) shell colour patterns $v s$. species, (2) shell colour patterns vs. location, (3) dark apertural band $v s$. species, and (4) dark apertural band vs. location. Each of the tables was analysed by using Pearson's Chi-squared test. When the expected frequency in the contingency table was less than 5, a Fisher exact test was performed instead of the Pearson's Chi-squared test (Bower, 2003). All the statistical analyses were performed in the $\mathrm{R}$ statistical environment version 3.1.3 ( $\mathrm{R}$ Core Team, 2015) with the significant p-values set at 0.05. (R script in Supplementary File 3).

\section{RESULTS}

\section{The molecular phylogeny of the Leptopoma species in Sabah}

A total of 660 nucleotide sites were aligned for the COI gene, 558 nucleotide sites for the $16 \mathrm{~S}$ gene and 627 nucleotide sites for ITS-1 (Supplementary File 4). Gaps were treated as missing data and were retained in all phylogenetic analyses. The aligned COI dataset consisted of 36.9\% GC content, 207 (31.4\%) parsimony informative, and 253 (38.3\%) variable sites. The aligned 16s gene had 33.3\% GC content with 276 (49.8\%) parsimony informative and 406 (73.3\%) variable sites. On the other hand, aligned ITS-1 gene had 48.6\% GC content, $158(25.2 \%)$ parsimony informative, and 274 (43.7\%) variable sites. Phylogenetic analyses were run for four datasets: three single-gene datasets (ITS-1, COI, 16S) and a concatenated dataset of the three genes. The tree was rooted on the outgroup Cyclophorus formosensis (Fig. 3).

Best-fitted models were selected based on the corrected Akaike Information Criterion (AICc); the models were TPM3uf + G for ITS -1 , TIM3 + G for $16 \mathrm{~S}$, TIM3ef $+\mathrm{G}$, TPM3uf + I, and TPM3uf $+\mathrm{G}$ respectively for first, second and third codons of COI. These models were used in both ML and BI analyses. Phylogenetic trees from the ML and BI analyses of the concatenated dataset showed no conflict in tree topology. The monophyly of the three Leptopoma species ( $L$. sericatum, L. pellucidum and L. atricapillum) in Sabah was consistently strongly supported (posterior probability of $100 \%$ and bootstrap support greater than 75 ).

\section{Phylogenetic signals in shell characters of the Leptopoma species}

Figure 4 shows the correlation between phylogeny and the quantitative and qualitative shell characters for L. sericatum, L. atricapillum and L. pellucidum. A phylogenetic signal test based on Pagel's $\lambda$ and Blomberg's $K$ showed that spiral ridges and the presence/absence of dark apertural band represented a strong signal with $\lambda=1$ and $\mathrm{K}>1(\mathrm{~K}=4.536$ for spiral ridges and $\mathrm{K}=1.114$ for dark apertural band) (Table 1). However, shell colour pattern, a character that is often used as a diagnostic character in traditional classification, showed a weak phylogenetic signal $(\lambda=0.997, K=0.234)$. Among the quantitative shell characters, shell height exhibited a strong signal according to Pagel's $\lambda$ although Blomberg's K gave a weak phylogenetic signal. The ratio of shell height to width $(\mathrm{SH} / \mathrm{SW})$ exhibited the weakest phylogenetic signal among all the shell characters $(\lambda=0, K=0.054)$. 


\section{Geographical Variation in Shell Forms}

242

243

244

245

246

247

248

249

250

251

252

253

254

255

256

257

258

259

260

261

262

263

264

265

266

267

268

269

270

271

272

273

274

275

276

Two-way ANOVA showed that all shell quantitative characters (except aperture height) differed between the two locations (Table 2, Fig. 5). In addition, all shell quantitative characters except shell width and aperture height also differed between the two species. There was interactive effect of species and location on the aperture height, shell spire height and ratio of shell height to width.

Chi-square analyses indicated a significant association between the frequencies of shell colour patterns and both species identity (Fisher's exact test: $p=0.0000$ ) and location (Fisher's exact test: $\mathrm{p}=0.0000$ ). On the other hand, there was a fairly significant association between the frequency of presence/absence of dark apertural band and species identity (Pearson's ChiSquared with Yates' continuity correction: $\left.X^{2}(1, \mathrm{~N}=249)=4.019, \mathrm{p}=0.0449\right)$ but not with location (Pearson's Chi-Squared with Yates' continuity correction: $\left.X^{2}(1, \mathrm{~N}=249)=1.5505, \mathrm{p}=0.2131\right)$. Both contingency tables are available in Table S5 \& S6 in Supplementary File 2. Overall, the shell characters considered in this study did not show consistent differences between $L$. pellucidum and L. sericatum since the differences in shell forms were coupled with geographical variations and interaction effects between geography and species.

\section{DISCUSSION}

This study presents the first molecular phylogeny investigation on genus Leptopoma in Sabah, one of the many understudied genera within the Cyclophoridae, and examines the concordance between morphology and phylogeny as well as geographical variation in shell form.

We found consistently significant support for the monophyly of the three morphologically similar Sabah Leptopoma species, L. pellucidum, L. sericatum and L. atricapillum. This finding is in concordance with the existing traditional morphology-based classification. For example, take the placement of Leptopoma pellucidum 6014 (Fig. 3) in our phylogeny, this population was previously assumed to be L. vitreum (Lesson, 1830) due to its uniformly white shell, but we have shown that it falls within the L. pellucidum clade, and this provides support to Vermeulen (1999)'s decision to assign L. vitreum from Sabah to $L$. pellucidum. In the case of L. pellucidum and L. sericatum, the presence of intermediate forms between the two species led Vermeulen to recognise them as being distinct on a purely provisional basis. In this study, results suggested that the two species could be unequivocally regarded as separate. In short, the findings of this study are in line with past research in this region which proposed that a combination of morphology and molecular approaches could improve taxonomy of land snails (Nantarat et al., 2014a, 2014b; Liew et al., 2009; Liew et al., 
277

278

279

280

281

282

283

284

285

286

287

288

289

290

291

292

293

294

295

296

297

298

299

300

301

302

303

304

305

306

307

308

309

310

311

312

313

314

315

316

2014). However, we aware that this findings still need to be verified with more specimens of both species from their entire distribution range outside of Sabah.

A morphological character is assumed to have strong phylogenetic signal when the same character clusters together within closely-related species (Blomberg et al., 2003). This could be a useful diagnostic indicator for species delimitation. The phylogenetic signal tests showed that spiral ridges had a significant phylogenetic signal $(\lambda=1, K>1)$. Distinct spiral ridges were present in L. sericatum and L. atricapillum, while L. pellucidum had weak spiral ridges. This indicated that weak spiral ridges might be an automorphy character for $L$. pellucidum which could be useful in discriminating $L$. pellucidum from $L$. sericatum and L. atricapillum. This result was in agreement with Vermeulen's (1999) work where spiral ridges were also used as a key to delimit L. pellucidum and L. sericatum.

The presence of a dark apertural band has not been observed in other cyclophorids and was not mentioned in other revisionary works of Leptopoma species. Results showed that the presence/absence of a dark apertural band exhibited a significant phylogenetic signal and does not associate with geography for two of the species. Nevertheless, association of dark apertural band with species identity was fairly significant. Our results showed that dark apertural band only present in some L. sericatum, with this character being observed at just two sites (i.e. Kinabatangan and the Tabin Wildlife Reserve area). However, when observing all the specimens in the BORNEENSIS collection, we found that such character is actually present in both $L$. pellucidum and L. sericatum. The apertural band of L. pellucidum was darker than L. sericatum. We also observed that dark apertural band is generally present in shells with thickened outer lip (gerontic shell) and a high abundance of shells that such character can be found in the Tabin Wildlife Reserve area. This might indicate a longer life span of Leptopoma species in the area, though this requires proper investigation. Overall, our findings here suggest that although this character shows a strong phylogenetic signal, it is not an appropriate character for species-level identification in Leptopoma.

Shell colour patterns are usually used as one of the key determinants to discriminate between species in traditional taxonomic classification. One of the sister taxa of Leptopoma, the species in genus Cyclophorus, was distinguished unambiguously based on shell patterns that were also supported by molecular data (Nantarat et al., 2014b). Compared to genus Cyclophorus, shell colour patterns of the L. sericatum and L. pellucidum, exhibited a weak phylogenetic signal. This case of shell colour pattern polymorphisms of the two Leptopoma species is similar to other well-known land snails such as Cepaea nemoralis and C. hortensis (Owen \& Bengtson, 1972; Ozgo \& Schilthuizen, 2012; Cameron \& Cook, 2012; Cameran, 2013). However, unlike Cepaea land snails that have been studied extensively, the causal mechanism for the Leptopoma land snail's diverse shell colour patterns is still unknown. This study also revealed that the Leptopoma species in Sabah exhibits idiosyncratic differences between locations in the degree of shell 
317

318

319

320

321

322

323

324

325

326

327

328

329

330

331

332

333

334

335

336

337

338

339

340

341

342

343

344

345

346

347

348

349

350

351

352

353

354

355

colour patterns polymorphism. For example, the Leptopoma population at Balambangan Island has more shell colour patterns as compared to the population at Kinabatangan. As a result, the geographically-associated variations in shell colour patterns and weak phylogenetic signal strongly indicate that this character is unreliable as a diagnostic character for the identification of the Leptopoma species considered in this study.

Significant inter- and intra-specific variations in quantitative shell characters have been noted both in family Cyclophoridae (Lee et al., 2012; Nantarat et al., 2014b) and in other gastropods (Kameda et al, 2007; Desouky \& Busais, 2012; Hirano et al., 2014). In Vermeulen's (1999) descriptions of $L$. sericatum and L. pellucidum, the ratio of shell height to width of $L$. sericatum is slightly smaller than $L$. pellucidum. However, intermediate in ratio of shell height to width between the two species occur and lead to weak phylogenetic signal in this character. From the phylogenetic signal test, only shell height produced a significant signal. Nevertheless, this study revealed a high degree of geographical variations in the quantitative shell characters; for example, both Leptopoma species from Balambangan Island were larger than the same species found in Kinabatangan. Previous studies suggested that land snails found on islands tend to undergo extensive morphological diversification (Johnson \& Black, 2000; Stankowski, 2011). In view of this, quantitative shell characters are thus not advisable as a diagnostic indicator to delimit among these two Leptopoma species in Sabah due to the strong influence of geographical variations.

While our findings reflected the reliability of 'hard' character (i.e. shell sculpture) over colour patterns and banding, and revealed considerable geographical variation in some shell characters, the findings from this study were based exclusively on Leptopoma species from Sabah. For future work to improve the taxonomy of this genus, the study needs to be extended to include larger numbers of specimens from a larger geographical area. In addition, more genetic markers and examination of reproductive characters are required to elucidate comprehensive phylogeny and morphological variation among the Leptopoma species

\section{CONCLUSION}

This study has revealed partial information on the phylogeny and morphology variations of all Leptopoma species in their entire distribution range. Despite its small geographical scale, the study has resolved taxonomic uncertainties of three Leptopoma species in Sabah and revealed notable variations in both the quantitative and qualitative shell characters for the species. From the findings, it is suggest that any future revisionary attempt of the taxonomy on the rest of $c a$. 100 Leptopoma species should consider the possible caveats in using the shell characters as the sole evidence and should include molecular markers in the study. Further studies that include more samples from a wider geographical reach are strongly recommended.

\section{ACKNOWLEDGEMENTS}


356 We would like to thank Cornelius Peter for his help with molecular lab work and Joumin 357 Rangkasan who assisted with fieldwork. This project was carried out by CCP and PSH as part of 358 their undergraduate honours degree dissertation. We thank Rudiger Bieler, Siong Kiat Tan and 359 an anonymous reviewer for their constructive comments.

360

361

362

363

364

365

366

367

368

369

370

371

372

373

374

375

376

377

378

379

380

381

382

383

384

385

386

\section{SUPPLEMENTARY FILES}

SUPPLEMENTARY FILE 1. Raw data for shell morphological analysis.

SUPPLEMENTARY FILE 2. Table S1. Specimen information; Table S2. Description of shell colour patterns, Table S3 \& S4. Results of the normality tests and homogeneity of variances tests prior to ANOVA; Table S5 \& S6. Frequency data for shell qualitative characters used in chisquare tests.

SUPPLEMENTARY FILE 3. R script for shell morphological data and phylogenetic signal analysis.

SUPPLEMENTARY FILE 4. FASTA file for the concatenated DNA sequences dataset for COI, $16 \mathrm{~S}$, and ITS-1.

\section{REFERENCES}

Blomberg, S. P., Garland, T., \& Ives, A. R. 2003. Testing for phylogenetic signal in comparative data: behavioral traits are more labile. Evolution, 57(4): 717-745.

Bower, K. M. 2003. When to use Fisher's exact test. In American Society for Quality, Six Sigma Forum Magazine, 2(4): 35-37.

Brown, M. B., \& Forsythe, A. B. 1974. Robust tests for the equality of variances. Journal of the American Statistical Association, 69(346), 364-367.

Cain, A. J., \& Sheppard, P. M. 1954. Natural selection in Cepaea. Genetics, 39(1): 89.

Cameron, R. A., \& Cook, L. M. 2012. Habitat and the shell polymorphism of Cepaea nemoralis (L.): interrogating the Evolution Megalab database. Journal of Molluscan Studies, 78(2), 179184.

Cameron, R. A. 2013. The poor relation? Polymorphism in Cepaea hortensis (OF Müller) and the Evolution Megalab. Journal of Molluscan Studies, 79(2), 112-117.

Colgan, D., Ponder, W. F., \& Eggler, P. E. 2000. Gastropod evolutionary rates and phylogenetic relationships assessed using partial 28S rDNA and histone H3sequences. Zoologica Scripta, 29(1): 29-63. 
387 Colgan, D. J., Ponder, W. F., Beacham, E., \& Macaranas, J. M. 2003. Gastropod phylogeny 388 based on six segments from four genes representing coding or non-coding and mitochondrial or 389 nuclear DNA. Molluscan Research, 23(2): 123-148.

390 Colgan, D. J., Ponder, W. F., Beacham, E., \& Macaranas, J. 2007. Molecular phylogenetics of 391 Caenogastropoda (Gastropoda: Mollusca). Molecular Phylogenetics and Evolution, 42(3): 717392737.

393 Darriba, D., Taboada, G. L., Doallo, R., \& Posada, D. 2012. jModelTest 2: more models, new 394 heuristics and parallel computing. Nature methods, 9(8): 772-772.

395

396

397

398

399

400

401

402

403

404

405

406

407 408

409

410

411

412

413

414

415

416

417

418

419

420

Desouky, M., \& Busais, S. 2012. Phylogenetic relationships of the land snail Eobania vermiculata (Müller, 1774) from Egypt and Saudi Arabia. A combined morphological and molecular analysis. The Journal of Basic \& Applied Zoology, 65(2): 144-151.

Folmer, O., Back, M., Hoeh, W., Lutz, R. \& Vrijenhoek, R. 1994. DNA primers for amplification of mitochondrial cytochrome c oxidase subunit I from diverse metazoan invertebrates. Mol. Mar. Biol. Biotech, 3: 294-299.

Godwin- Austen, L., \& HH, C. 1891. 4. On a collection of land-shells made in Borneo by Mr. A. Everett, with Descriptions of supposed new species. In Proceedings of the Zoological Society of London, 59(1): 22-48.

Grateloup, JPS. de. 1840. Memoire sue plusieurs especes de coquilles nouvellesou peu connues de mollusque exotiques, vivants, terrestres, fluviatiles et marins. Actes de la Societe Linneenne de Bordeaux 11: 389-455.

Gude, G. K., 1921.Mollusca. III. Land Operculates (Cyclophoridea, Truncatellidae, Assimineidae, Helicinidae) in The Fauna of British India, London, i-xiv, 1-386, 42figs, 2 pls

Hall, T. A. 1999. BioEdit: a user-friendly biological sequence alignment editor and analysis program for Windows 95/98/NT. In Nucleic acids symposium series, 41: 95-98.

Harmon L. J, Jason T. W, Chad D. B, Richard E. G, \& Wendell Challenger. 2008. GEIGER: investigating evolutionary radiations. Bioinformatics, 24:129-131.

Hillis, D. M., \& Dixon, M. T. 1991. Ribosomal DNA: molecular evolution and phylogenetic inference. The Quarterly review of biology, 66(4), 411-453.

Hirano, T., Kameda, Y., Kimura, K., \& Chiba, S. 2014. Substantial incongruence among the morphology, taxonomy, and molecular phylogeny of the land snails Aegista, Landouria, Trishoplita, and Pseudobuliminus (Pulmonata: Bradybaenidae) occurring in East Asia. Molecular phylogenetics and evolution, 70: 171-181.

Huelsenbeck, J.P., Ronquist, F.R., Nielsen, R., Bollback, J.P., 2001. Bayesian inference of phylogeny and its impact on evolutionary biology. Science 294, 2310-2314. 
421 Johnson, M.S. \& Black, R. 2000. Associations with habitat versus geographic cohesiveness: size 422 and shape of Bembicium vittatum Philippi (Gastropoda: Littorinidae) in the Houtman Abrolhos 423 Islands. Biological Journal of the Linnean Society. 71:563-580.

424 Jonges, K. 1980. Genital ducts in several species of the cyclophorid genus Leptopoma (Mollusca, 425 Mesogastropoda). Bijdragen tot de Dierkunde, 50: 292-302.

426 Kameda, Y., Kawakita, A., \& Kato, M. 2007. Cryptic genetic divergence and associated 427 morphological differentiation in the arboreal land snail Satsuma (Luchuhadra) largillierti 428 (Camaenidae) endemic to the Ryukyu Archipelago, Japan. Molecular phylogenetics and 429 evolution, 45(2): 519-533.

430 Kessing, B., Croom, H., Martin, A., McIntosh, C., McMillan, W. O., \& Palumbi, S. 1989. The 431 simple fool's guide to PCR. Department of Zoology, University of Hawaii, Honolulu, 1-23.

432 Kobelt, W. 1902. Cyclophoridae. Das Tierreich 16: 1-662.

433 Lee, Y. C., Lue, K. Y., \& Wu, W. L. 2008a. A molecular phylogenetic investigation of 434 Cyathopoma (Prosobranchia: Cyclophoridae) in East Asia. Zoological Studies, 47(5): 591-604.

435 Lee, Y. C., Lue, K. Y., \& Wu, W. L. 2008b. Molecular evidence for a polyphyletic genus 436 Japonia (Architaenioglossa: Cyclophoridae) and with the description of a new genus and two 437 new species. Zootaxa. 1792: 22-38.

438 Lee, Y. C., Lue, K. Y., \& Wu, W. L. 2012. The Phylogeny and Morphological Adaptations of 439 Cyclotus taivanus ssp.(Gastropoda: Cyclophoridae).Malacologia, 55(1), 91-105.

440 Lesson, R. P. 1831. Mollusca. - In: voyage autour du monde, éxécuté par ordre du Roi, sur la 441 corvette de Sa Majesté, La Coquille, pendant les années 1822-1825. 2(1): 1-471. Paris.

442 Liew, T. S., Schilthuizen, M., \& Vermeulen, J. J. 2009. Systematic revision of the genus 443 Everettia Godwin-Austen, 1891 (Mollusca: Gastropoda: Dyakiidae) in Sabah, northen Borneo. 444 Zoological Journal of the Linnean Society, 157(3): 515-550.

445 Liew, T. S., Vermeulen, J. J., Marzuki, M. E., \& Schilthuizen, M. 2014. A cybertaxonomic 446 revision of the micro-land snail genus Plectostoma Adam (Mollusca, Caenogastropoda, 447 Diplommatinidae), from Peninsular Malaysia, Sumatra and Indochina. ZooKeys, 393: 1-107.

448 Laidlaw, F. F. 1937. Notes on the land Mollusca from Mount Kinabalu, British North 449 Borneo. The Bulletin of the Raffles Museum, 13: 177-189.

450 Metcalfe W., 1851. An enumeration of species of recent shells, received by W.J. Hamilton. Esq., 451 from Borneo, in November 1850. With descriptions of new species. Proceedings of the 452 Zoological Society of London 19: 70-74. 
453 Miller, M.A., Pfeiffer, W., \& Schwartz, T. 2010. Creating the CIPRES Science Gateway for 454 inference of large phylogenetic trees. In, Proceedings of the Gateway Computing Environments 455 Workshop (GCE), 14 Nov. 2010, New Orleans, LA pp 1-8.

456 Nantarat, N., Tongkerd, P., Sutcharit, C., Wade, C. M., Naggs, F., \& Panha, S. $2014 a$. 457 Phylogenetic relationships of the operculate land snail genus Cyclophorus Montfort, 1810 in 458 Thailand. Molecular Phylogenetics and Evolution, 70: 99-111.

459 Nantarat, N., Wade, C. M., Jeratthitikul, E., Sutcharit, C., \& Panha, S. 2014b. Molecular 460 evidence for cryptic speciation in the Cyclophorus fulguratus (Pfeiffer, 1854) species complex 461 (Caenogastropoda: Cyclophoridae) with description of new species. PloS one, 9(10), e109785.

462 Owen, D. F., \& Bengtson, S. A. 1972. Polymorphism in the land snail Cepaea hortensis in 463 Iceland. Oikos, 218-225.

464 Ożgo, M., \& Schilthuizen, M. 2012. Evolutionary change in Cepaea nemoralis shell colour over 46543 years. Global Change Biology, 18(1), 74-81.

466 Pagel, M. 1999. The maximum likelihood approach to reconstructing ancestral character states of 467 discrete characters on phylogenies. Systematic biology, 612-622.

468 Paradis E., Claude J. \& Strimmer K. 2004. APE: analyses of phylogenetics and evolution in R 469 language. Bioinformatics, 20: 289-290.

470 Pfeiffer, L., 1851. Descriptions of forty-three new species of Cyclostomatacea, from collection 471 of H. Cumming, Esq. Proceedings of Zoological Society of London, 19: 242-251.

472 R Core Team. 2015. R: A language and environment for statistical computing. R Foundation for 473 Statistical Computing, Vienna, Austria. URL http://www.R-project.org/.

474 Ratnasingham, S., \& Hebert, P. D. 2007. BOLD: The Barcode of Life Data System (http://www. 475 barcodinglife. org). Molecular Ecology Notes, 7(3): 355-364.

476 Revell, L. J. 2012. phytools: An R package for phylogenetic comparative biology (and other 477 things). Methods Ecol. Evol, 3: 217-223.

478 Sarasin P, Sarasin F. 1899. Die Land-Mollusken von Celebes. Wiesbaden: Kreidel. 15-25.

479 Schilthuizen, M., \& Rutjes, H. A. 2001. Land snail diversity in a square kilometre of tropical 480 rainforest in Sabah, Malaysian Borneo. Journal of Molluscan Studies, 67(4): 417-423.

481 Shapiro, S. S., \& Wilk, M. B. 1965. An analysis of variance test for normality (complete 482 samples). Biometrika, 52(3-4), 591-611.

483 Stamatakis, A. 2014. RAxML Version 8: A tool for Phylogenetic Analysis and Post-Analysis of 484 Large Phylogenies. Bioinformatics 10.1093/bioinformatics/btu033. 
485 Stankowski, S. 2011. Extreme, continuous variation in an island snail: local diversification and 486 association of shell form with the current environment. Biological Journal of the Linnean Society, 487 104(4): 756-769.

488 Uchidal, R., Yahya, B. E., Ahmad, A. H., Sapaat, A., \& Tomiyamal, K. 2013. Land snail fauna 489 of Sabah, Borneo, Malaysia. Venus. 71(1/2): 49-59.

490 Vermeulen, J. J. 1999. Notes on the non-marine molluscs of the island of Borneo 9. The genera 491 Cyclophorus, Leptopoma, and Craspedotropis (Gastropoda Prosobranchia: 492 Cyclophoridae). Basteria, 63(4/6): 139-163.

493 Zar, J.H .1999. Biostatistical Analysis, 4th ed., New Jersey: Prentice-Hall Inc

494 Zilch, A., 1954. Die Typen und Typoide des Natur-Museums Senckenberg, 13 Mollusca, 495 Cyclophoridae, Cyclophorinae-Cyclophoreae (1). Archiv für Molluskenkunde 83:141-157.

496

497 


\section{Figure 1}

Distribution map of four Leptopoma species in Sabah based on the records from BORNEENSIS Mollusca collection, Universiti Malaysia Sabah and localities of molecular samples.

Each circle represents a collection lot for a single Leptopoma species with the size of circle indicating the number of specimens in the lot (smallest circle $=1$ individuals; largest circles $=140$ individuals). The insets $(A)$ and $(B)$ show the sympatric populations of $L$. sericatum and L. pellucidum (i.e. on Balambangan Island and in Kinabatangan), which were used for shell morphological analysis. Orange triangles show localities of specimens for molecular study.

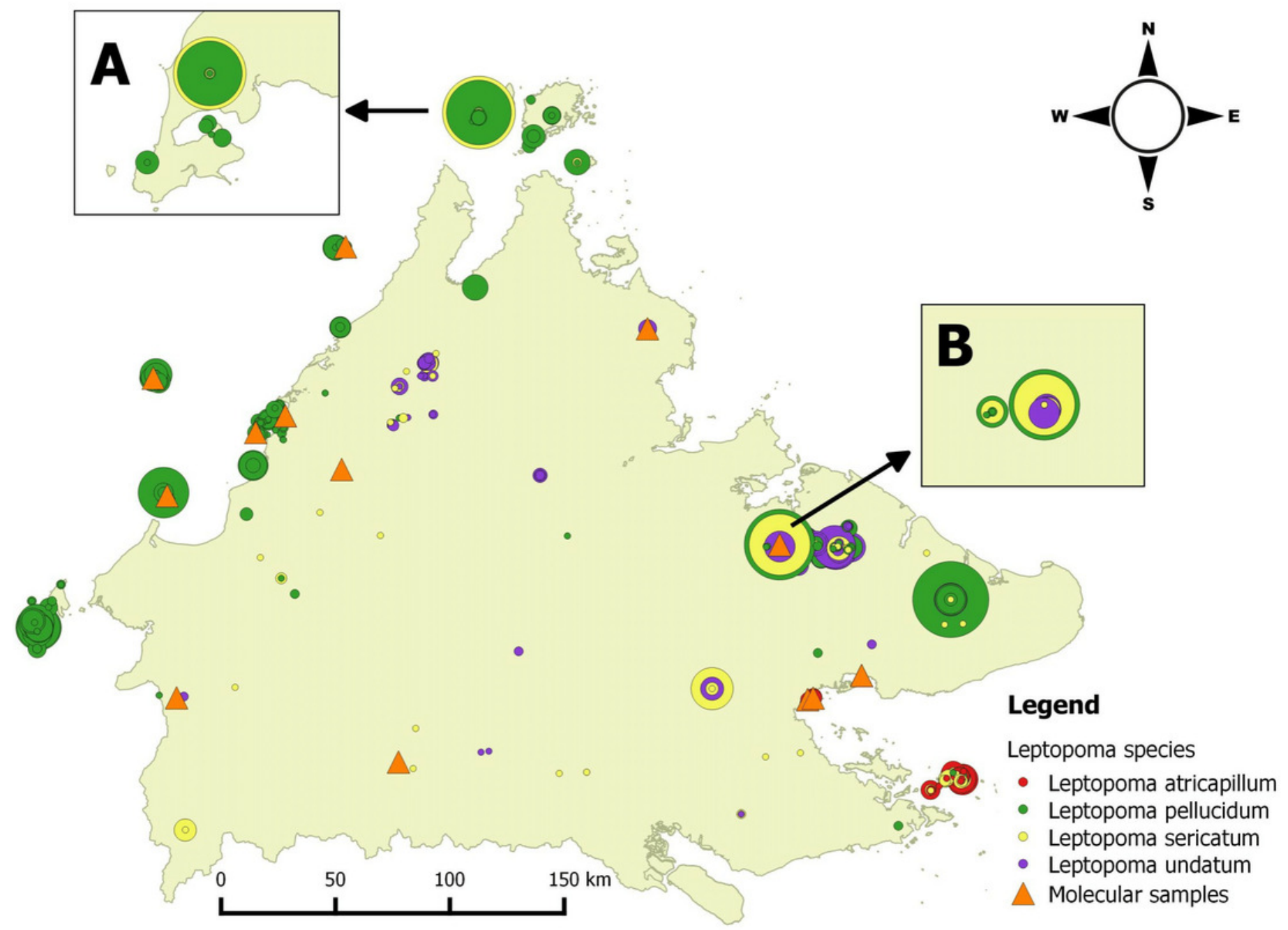




\section{Figure 2}

Qualitative and quantitative shell characters included in the study were assessed on the basis of the shell apertural view.

(A) The five shell quantitative measurements: SH - Shell height, SW - Shell width, AH -

Aperture height, AW - Aperture width, SpH - Shell spire height. (B) Spiral ridges: Left - Strong, Right - Weak. (C) The eight distinct shell colour patterns identified in the study. (D) Dark apertural band: Left - Presence, Right - Absence.

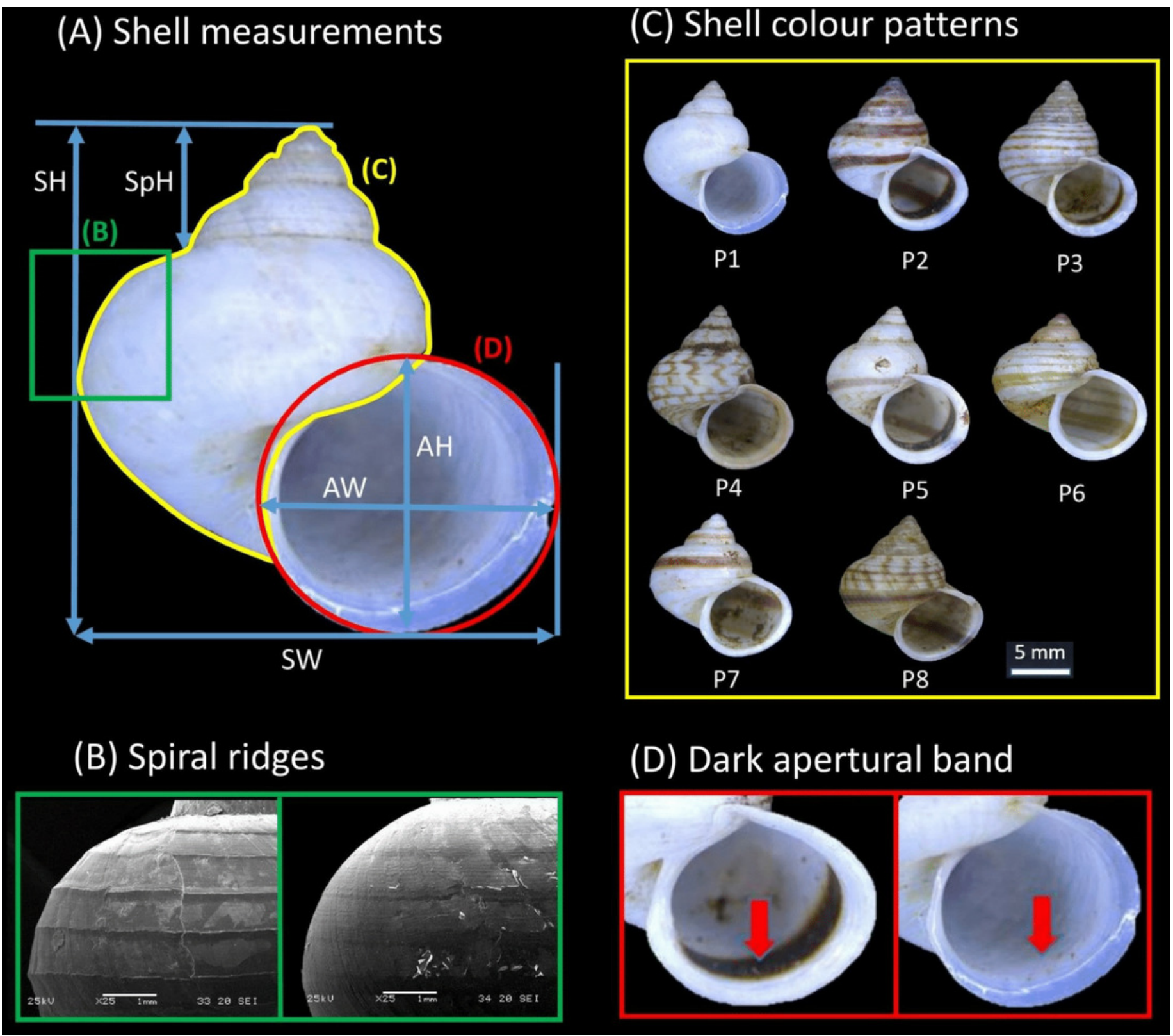




\section{Figure 3}

Bayesian inference tree of Leptopoma spp. based on concatenated dataset of 16S, COI and ITS-1.

Support values on branches are Bayesian posterior probability (BI) followed by maximum likelihood (ML) bootstrap value. Internal branches with ML bootstrap value $=100 \%$ and PP value $=100$ were not represents in the figure. The number shown beside each specimen of Sabah Leptopoma is the relevant specimen number (Table S1 in Supplementary File 2), and the specimens with asterisk are non-Borneo's Leptopoma species (i.e sequences obtained from Genbank). Clades A, B and C indicate the three Sabah species of focal interest. Scale bar for branch length $=0.1$ substitutions per site.

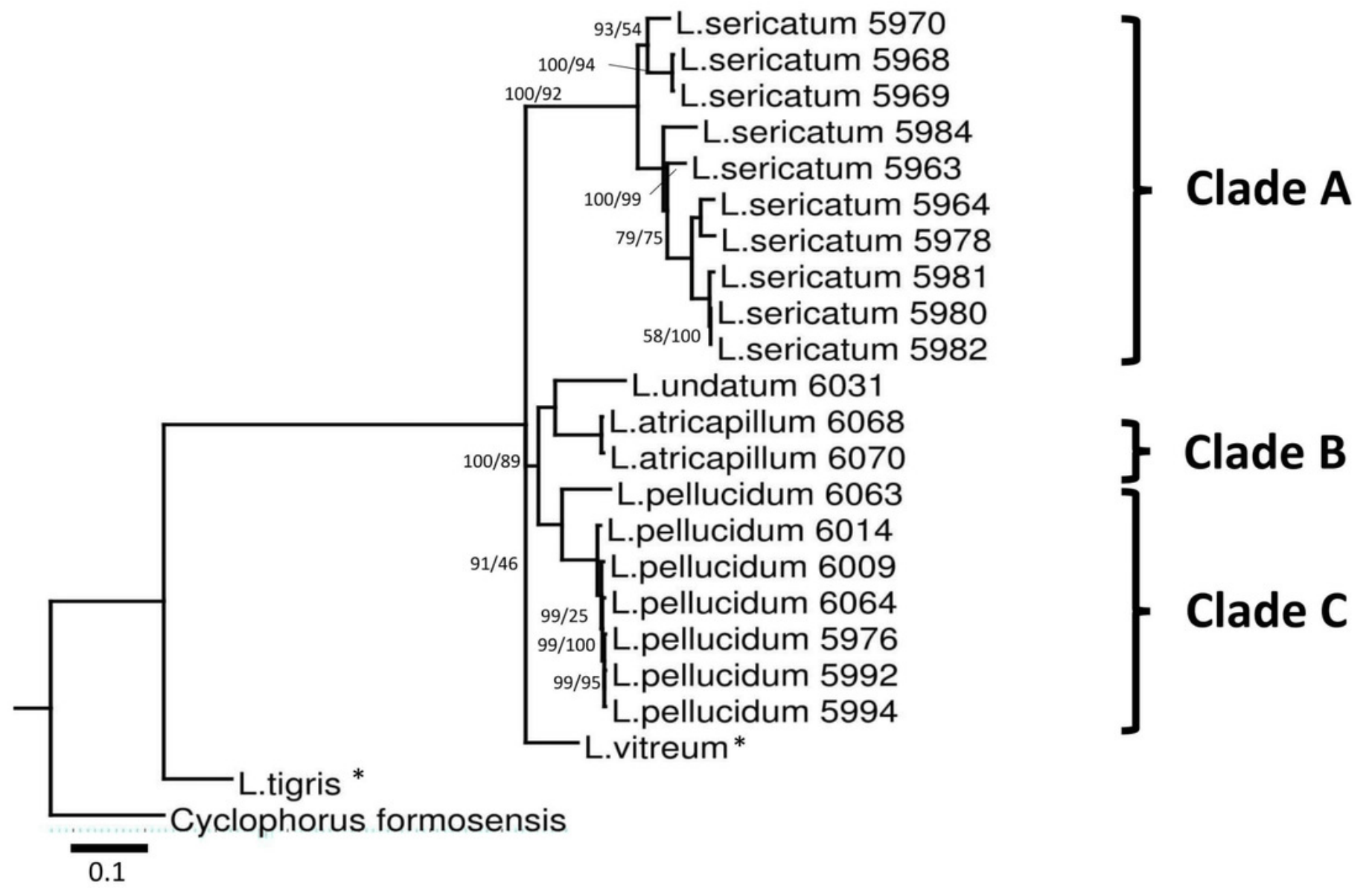




\section{Figure 4}

Shell quantitative and qualitative shell characters as mapped on to the phylogenetic tree.

Tree as in Figure 3 with the juvenile specimens were dropped from the tree and only the 14 adult specimens of the three Leptopoma species were retained. Different categories of the three qualitative shell characters: spiral ridges, shell colour patterns and dark apertural band (Figures 1A, 1B, 1C respectively) were represented by different colour of the squares; and the six shell quantitative measurements: shell height, shell width, aperture height, aperture width, shell spire height and ratio of shell height to width were represented by the size of the circle.

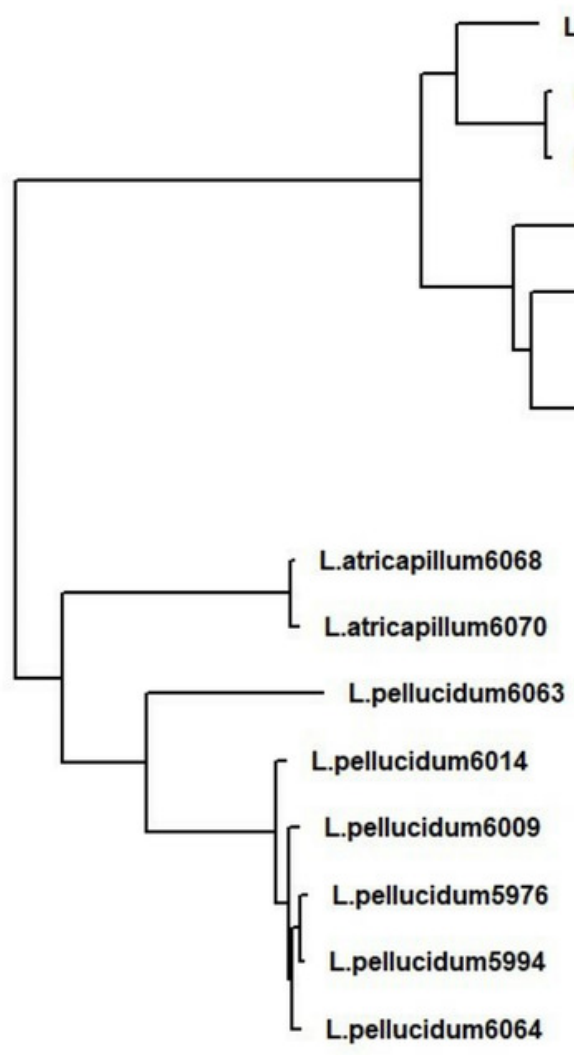

L.sericatum 5970

L.sericatum5968

L.sericatum5969

L.sericatum5984

L.sericatum 5963

L.sericatum59

L.sericatum 5980
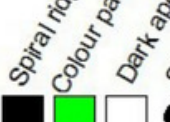

हर
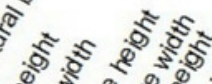

क के के

1000
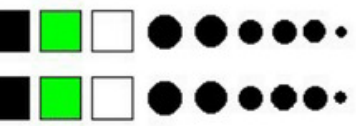

$\square \square \square \bullet \bullet \bullet \bullet \bullet$.

$\square \square \square$

प 10000

प $\square 000$

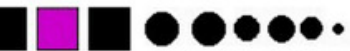

प $\square 0000$.

$\square \square 0000$.

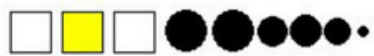

$\square \square \square 0000$

$\square \square \square 0000$.

$\square \square \square 0000$.

$\square \square \square 0000$.

$\square \square \square 0000$.
Spiral ridges

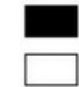

distinct ridges

weak ridges

Shell colour patterns

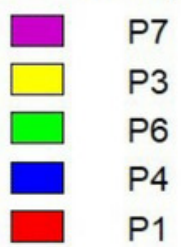

Dark apertural band

presence

absence 


\section{Figure 5}

Boxplots show the differences of the six quantitative measurements of shell for the Leptopoma pellucidum and L. sericatum in each of the two locations (Balambangan Island and Kinabatangan region).

Grey boxplot indicated sample from Balambangan Island (BI) and white boxplot indicated sample from Kinabatangan (K). Sample sizes for each dataset were: BI-pellucidum ( $n=45)$; Kpellucidum ( $n=90)$; BI-sericatum $(n=46)$; K-sericatum $(n=68)$. 


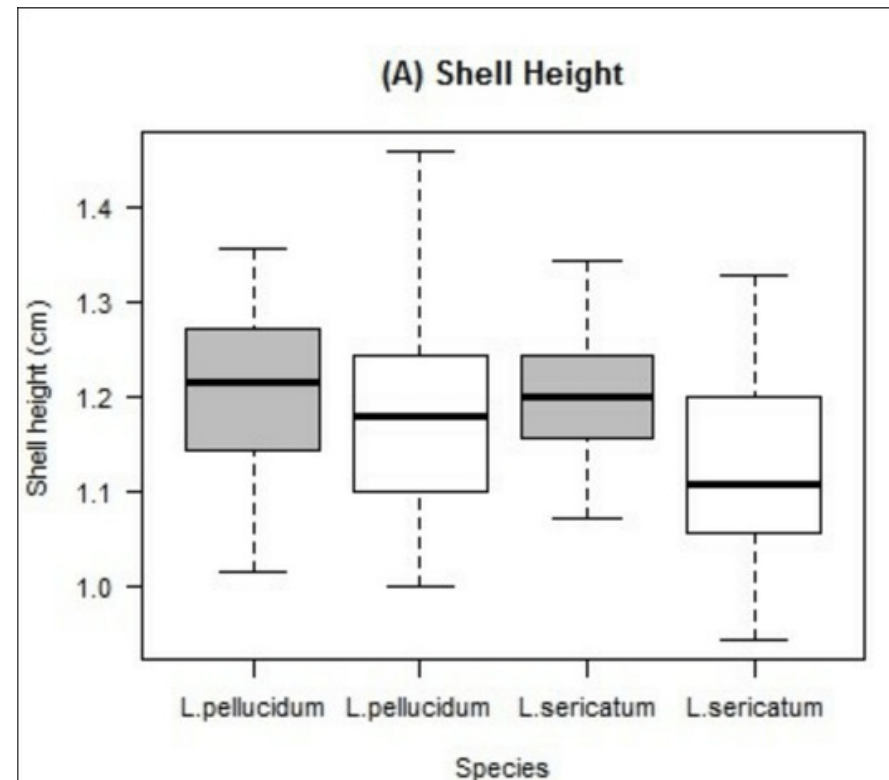

(C) Aperture Height

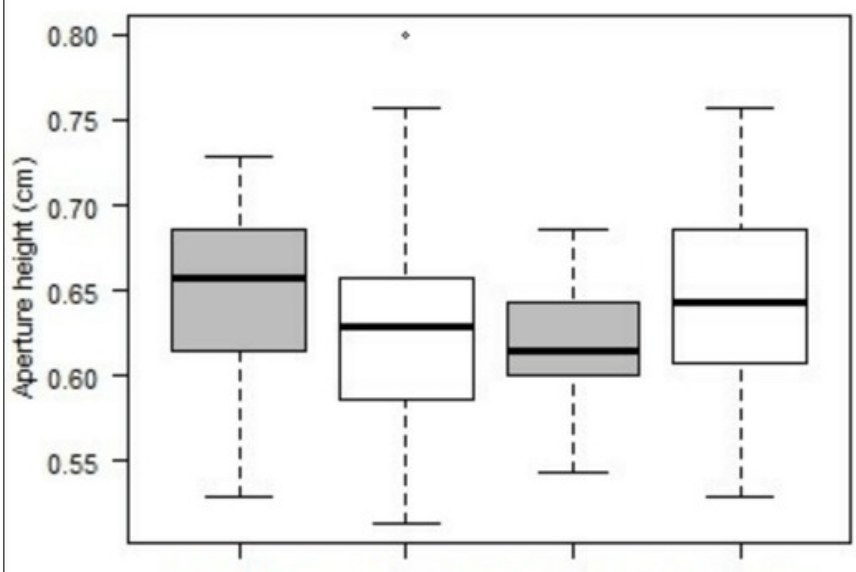

L.pellucidum L.pellucidum L.sericatum L.sericatum

Species

(E) Shell Spire Height

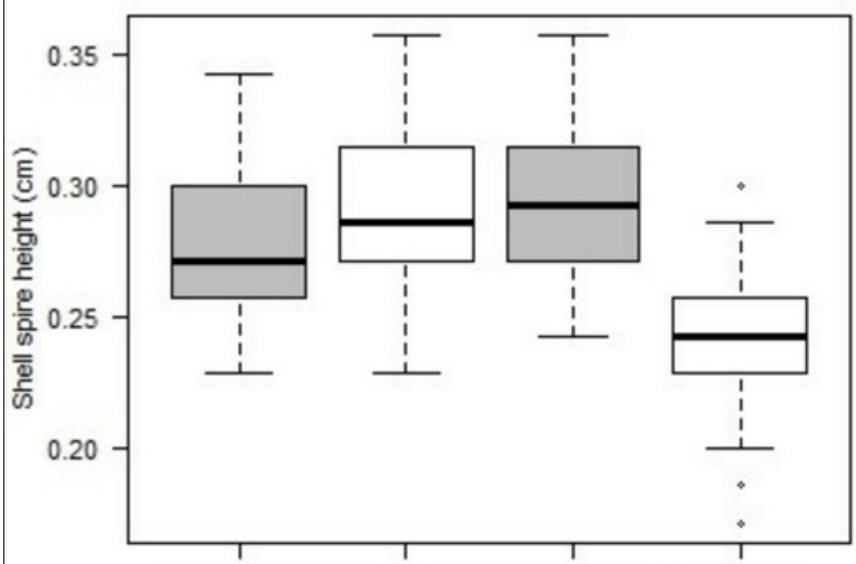

L.pellucidum L.pellucidum L.sericatum L.sericatum

Species

PeerJ reviewing PDF | (2017:07:19051:2:0:NEW 11 Oct 2017)

\section{(B) Shell Width}

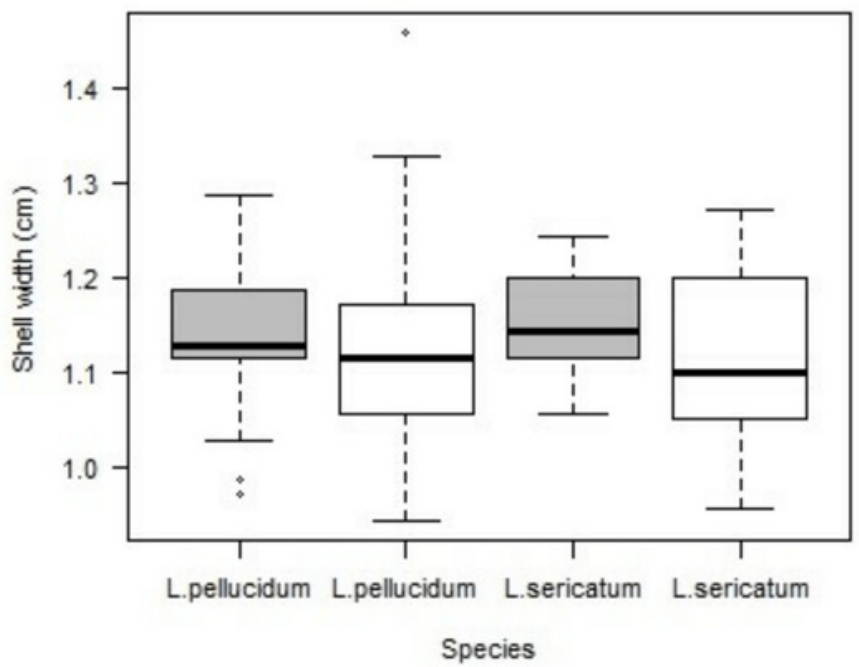

(D) Aperture Width

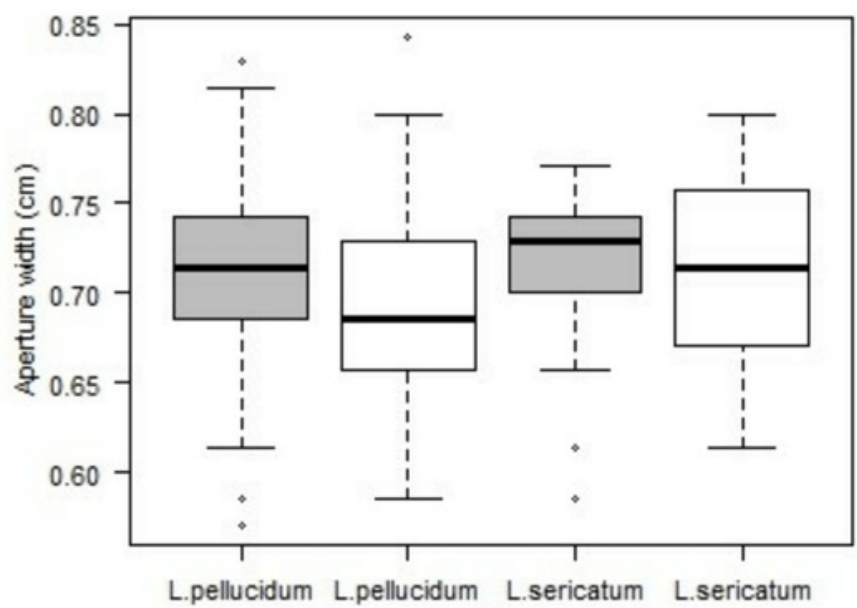

Species

(F) Ratio of shell height and width

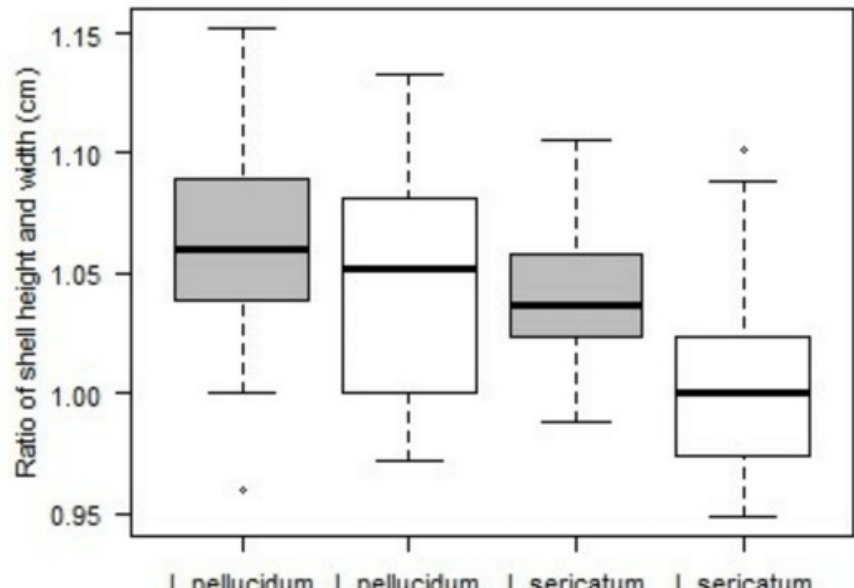

Species 


\section{Table $\mathbf{1}$ (on next page)}

Phylogenetic signal test result acquired from Pagel's $\lambda$ method and Blomberg's $K$ method. Values equal to 1 or more than 1 were bolded.

Abbreviations: SH, shell height; SW, shell width; AH, aperture height; AW, aperture width; $\mathrm{SpH}$, shell spire height; $\mathrm{SH} / \mathrm{SW}$ ratio of shell height and width. 
1 Table 1. Phylogenetic signal test result acquired from Pagel's $\lambda$ method and Blomberg's K method.

2 Values equal to 1 or more than 1 were bolded.

\begin{tabular}{|c|c|c|c|c|c|c|}
\hline Shell traits & $\begin{array}{l}\text { Lambda } \\
(\lambda)\end{array}$ & $\begin{array}{l}\text { likelihood } \\
\text { score } \\
\text { (alternative } \\
\text { model) }\end{array}$ & $\begin{array}{l}\text { likelihood } \\
\text { score (null } \\
\text { model, } \lambda=0 \text { ) }\end{array}$ & p-value & $\mathbf{K}$ & $\mathbf{P}$ \\
\hline Patterns & 0.997 & -17.986 & -21.906 & 0.005 & 0.234 & 0.014 \\
\hline Spiral ridges & 1.000 & -3.654 & -9.704 & 0.0005 & 4.490 & 0.001 \\
\hline \multicolumn{7}{|l|}{ Dark ring } \\
\hline $\mathbf{A H}$ & 0.998 & -15.969 & -21.266 & 0.001 & 0.518 & 0.001 \\
\hline $\mathbf{A W}$ & 0.866 & -16.641 & -21.395 & 0.002 & 0.437 & 0.001 \\
\hline SpH & 0.894 & -17.850 & -22.426 & 0.002 & 0.444 & 0.003 \\
\hline SH & 1.000 & -24.197 & -29.651 & 0.0007 & 0.567 & 0.001 \\
\hline SW & 0.829 & -24.040 & -29.651 & 0.001 & 0.442 & 0.001 \\
\hline SH/SW & 0 & 17.147 & 17.147 & 1 & 0.056 & 0.320 \\
\hline
\end{tabular}

3 Abbreviations: SH, shell height; SW, shell width; AH, aperture height; AW, aperture width; $\mathrm{SpH}$,

4 shell spire height; $\mathrm{SH} / \mathrm{SW}$ ratio of shell height and width. 


\section{Table 2 (on next page)}

Two-way ANOVA for the effect of geographical variation and species identity on six quantitative shell traits. Significant $p$-values were bolded.

Abbreviations: SH, shell height; SW, shell width; AH, aperture height; AW, aperture width; $\mathrm{SpH}$, shell spire height; $\mathrm{SH} / \mathrm{SW}$, ratio of shell height and width. 
1 Table 2. Two-way ANOVA for the effect of geographical variation and species identity on six $q$ 2 uantitative shell traits. Significant p-values were bolded.

3

\begin{tabular}{llllllllll}
\hline & \multicolumn{3}{c}{ Geographical region } & \multicolumn{3}{c}{ Species identity } & \multicolumn{3}{c}{ Geographical* Species } \\
\cline { 2 - 10 } & df & F & P-value & df & F & P-value & df & F & P-value \\
\hline SH & 1 & 18.88 & $\mathbf{2 . 0 3 e - 0 5}$ & 1 & 12.763 & $\mathbf{0 . 0 0 0 4}$ & 1 & 3.551 & 0.0607 \\
\hline SW & 1 & 5.376 & $\mathbf{0 . 0 2 1 2}$ & 1 & 0.104 & 0.7473 & 1 & 0.586 & 0.4447 \\
\hline AH & 1 & 0.086 & 0.770 & 1 & 0.000 & 0.987 & 1 & 16.185 & $\mathbf{7 . 6 6 e - 0 5}$ \\
\hline AW & 1 & 4.235 & $\mathbf{0 . 0 4 0 7}$ & 1 & 4.399 & $\mathbf{0 . 0 3 7 0}$ & 1 & 1.994 & 0.1592 \\
\hline SpH & 1 & 24.92 & $\mathbf{1 . 1 4 e - 0 6}$ & 1 & 36.33 & $\mathbf{6 . 0 8 e - 0 9}$ & 1 & 80.01 & $<\mathbf{2 e - 1 6}$ \\
\hline SH/S & 1 & 17.36 & $\mathbf{4 . 2 9 e - 0 5}$ & 1 & 62.10 & $\mathbf{1 . 0 7 e - 1 3}$ & 1 & 5.53 & $\mathbf{0 . 0 1 9 5}$ \\
W & & & & & & & & &
\end{tabular}

4 Abbreviations: SH, shell height; SW, shell width; AH, aperture height; AW, aperture width; SpH, 5 shell spire height; SH/SW, ratio of shell height and width. 